\title{
TUNNEL PORTAL INSTABILITY IN LANDSLIDE AREA AND REMEDIAL SOLUTION: A CASE STUDY
}

\author{
Farhad Farhadi Ayoublou $^{a, *}$, Majid Taromi $^{b}$, Abbas Eftekhari $^{c}$ \\ a Amirkabir University of Technology, Faculty of Engineering, Department of Civil Engineering, Hafez Street, No. \\ 350, 4413-15875 - Tehran, Iran \\ ${ }^{b}$ Islamic Azad University of South Tehran Branch, Faculty of Engineering, Department of Civil Engineering, \\ Karimkhan-e-Zand Street, No. 223, 1584743311 - Tehran, Iran \\ ${ }^{c}$ Kashan University, Faculty of Engineering, Department of Mining Engineering, 6th kilometer from Ghotbe \\ Ravandi Boulevard, 8731753153 - Kashan, Iran \\ * corresponding author: farhadfarhadi18964@gmail.com
}

\begin{abstract}
The construction of tunnel portals in mountainous or slope areas often involves problems, which are closely related to factors, such as slope topography, geology, geotechnics, construction geometry and the tunnel excavation method. The activation of landslides or the acceleration of these events is one of the main challenges faced in the construction of tunnel portals. In this paper, we address the instability problem in Sabzkuh tunnel portal that has been excavated with a complex geological profile and high seismicity in Iran's High Zagros region. The complexity and intense heterogeneity in geological formations, land acquisition problems and the lack of appropriate monitoring programs led to the instability of the tunnel portal. The excavation process started without applying appropriate techniques for a ground stabilization. The use of inappropriate tunnel excavation methods for this unstable geological structure resulted in an activation of an old Solaghan fault and several collapses in the tunnel. Crossing the collapsed areas and reinforcing the tunnel portal took about 7 months and imposed heavy costs on the project. This case study deals with the importance of the choice of the site location, ground and underground monitoring, analysing and summarizing the collected data in order to prepare a geological model before and during the construction process.
\end{abstract}

Keywords: Slope instability, collapse, landslide, Sabzkuh Tunnel, remedial solution.

\section{INTRODUCTION}

Sabzkuh water conveyance tunnel with a length of 10,617 meters is being excavated using both conventional and mechanized techniques in Chaharmahal and Bakhtiari Province across the Iran's central zone and Zagros and with a close distance from the $\mathrm{Za}-$ gros Fault in the High Zagros region. The Naghan earthquake on 7 May 1997 with a 6 magnitude on the Richter scale and the resulting landslide in the rural areas of Saki-Abad and at the southern tunnel entrance in the southern part of Choghakhor Lake caused a structural failure in the region under the study.

Due to geological complexities, high groundwater levels in the region, and the inability of the project employer to acquire enough land to build the tunnel entrance in an appropriate location, the slope stability in the Sabzkuh tunnel entrance faced a challenge. After constructing tranches and before starting the tunnel excavation, signs of slope instability were observed. However, as these signs were not taken seriously and there were no proper monitoring programs as well as guidelines and appropriate measures for stabilization, the instability level was intensified. After excavation of 35 meters from the tunnel using conventional methods, the steep slope of layers, poor geotechnical characteristics of soil layers, old landslide activation, poor drainage, and the use of unfavourable tunnel excavation methods caused a funnel like collapse in tunnel in such a way that the cave-in measured about 22 meters in diameter on the ground level. Crossing through the collapsing area took about seven months to complete and it imposed high costs on the project and consequently its schedule [1, 2].

This paper presents a case study of the instability at Sabzkuh tunnel portal, which is located in an area with a high potential for landslides, faults and the complex geological structures that were not known before starting the tunnelling operations. After describing the geological characteristics and geotechnical conditions of the study area, the importance of monitoring systems to identify landslide and instability potentials before and during the tunnel excavation was estimated using various methods. Afterwards, the slope instability and tunnel collapse mechanisms were investigated. Then, the collected data were accumulated in a database in order to analyse the landslide profile, find slope improvement strategies, and continue the excavation operation. 


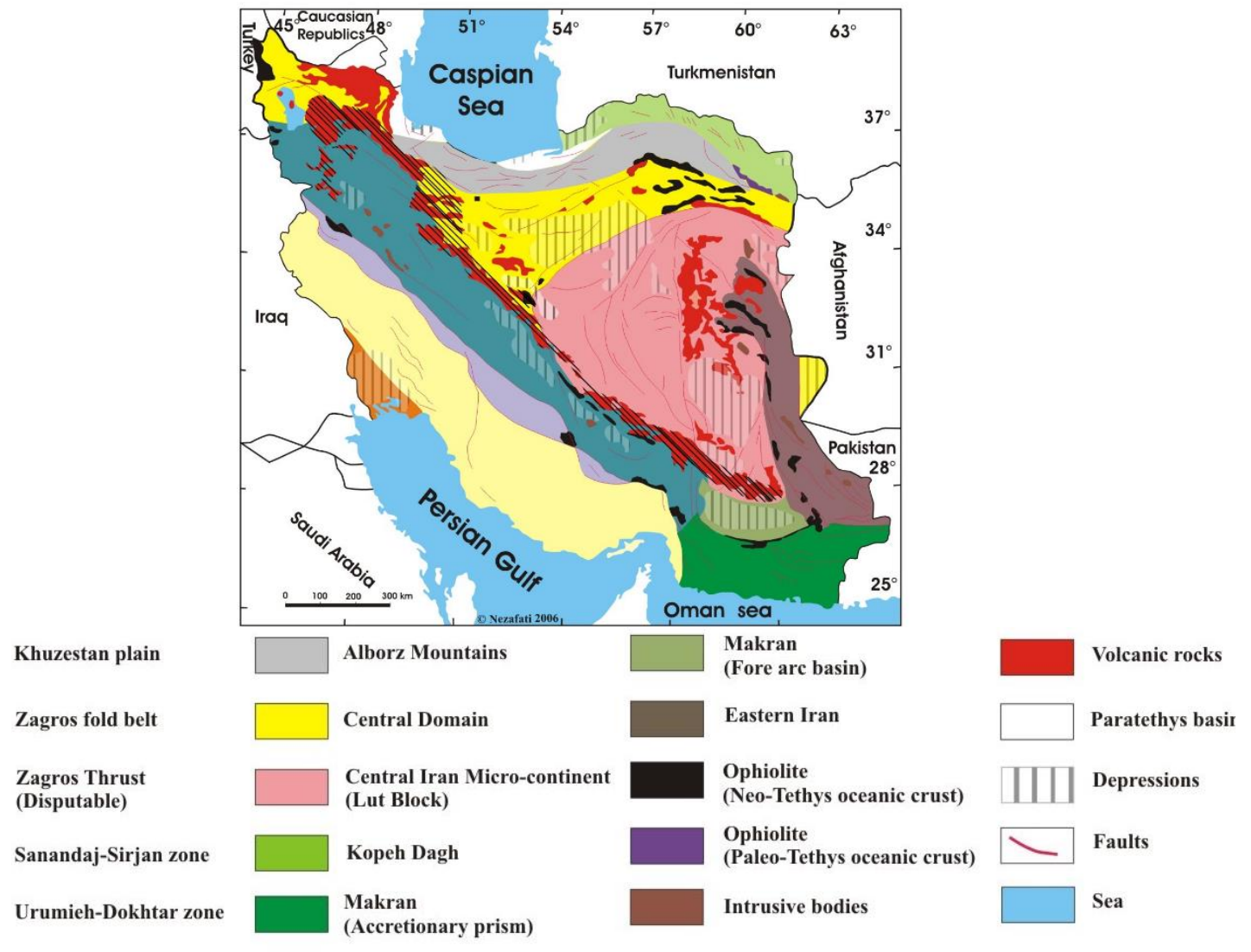

Figure 1. Map of geological zone in Iran [3].

\section{General GeOlogy}

The studied region is located in the southeastern part of Chaharmahal and Bakhtiari Province in Iran. The water transfer route from Sabzkuh to Choghakhor is located in wrinkled mountain belts of Zagros, which is located in the middle part of the Alpine orogeny belt and is considered as one of the youngest Cenozoic orogenies. In addition, the tunnel portal is located in the southern part of the lake of Choghakhor Dam and the north of Kalar Mountain Range. Zagros thrust encompasses the highest Zagros Mountains (Zardkuh 4 400meters, Oshtorankuh 4170 meters, and Dena 4000 meters) and thus it is called High Zagros (Figure 1).

\subsection{Geology of Study area}

The study region, Solaghan Fault is located along northeast Sabzkuh syncline at N130 and a dip direction to the southwest in the southwestern part of Choghakhor Lake. This fault has caused Paleozoic units and clastic-rock units on the fault path, have been placed on recent sediments. There are many springs such as Saki Abad spring running along this fault. The fault zone is not visible across the tunnel, but Solaghan fault can be detected on the satellite images because of the height differences caused by the fault and the border that is placed between the vegetation and mountains. Solaghan Fault is placed on a rupture structure with a dip of 40 to 65 degree and the fault zone is located in a distance of $0+380$ $(10+237)$ meters from the tunnel portal. This fault has branches that spread from the high depths to the surface and are called the STF. In the footwall and headwall of the fault, two thrust faults have also been detected and are regarded as the footwall and headwall of the Solaghan fault zone. The function of the fault caused the disturbance and complexity of geological layers in the region, which is displayed in Figure 2 The STF1 fault is the first fault in the tunnel portal and is regarded as one of the branches of footwalls of Solaghan Fault. There is no external evidence for the existence of the fault in the area of the tunnel portal. This fault has been discovered based on the geological log of boreholes and the data from the geophysical study. These data show that the fault has a dip close to Solaghan Fault and in the same direction. The fault zone is located in a distance of $0+235$ meters from the northern tunnel portal. The fault is located on a rupture structure with a dip of about 25 to 60 degrees (Figure 2).

\section{Geotechnichl Study}

The local evidence and the data from the boreholes indicate that the geology of the area is composed of alluvium and debris-flow deposits in the vicinity of the heights. The results obtained from the observations 


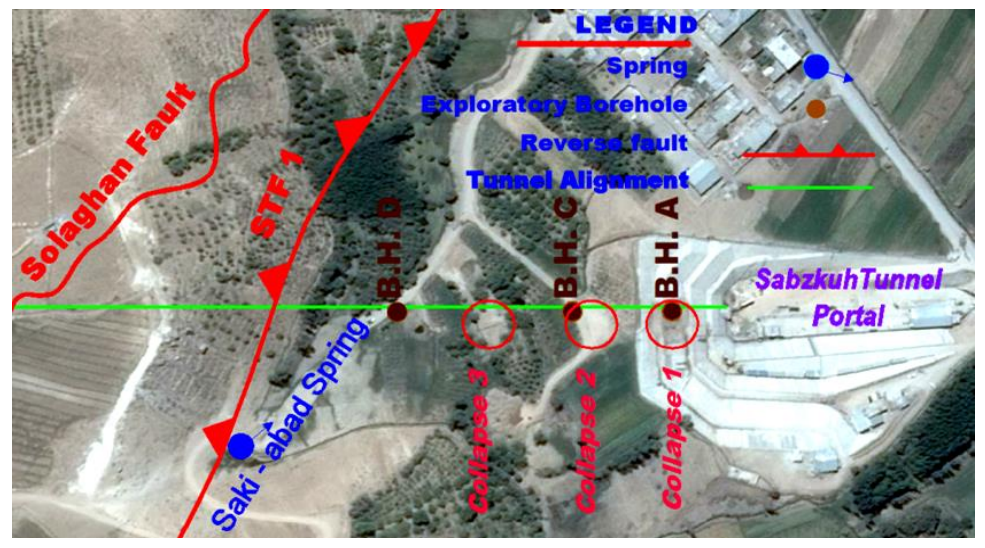

Figure 2. The plan of the study area.

and the position of drilled boreholes indicate that the geological structure in the flood plain is different from that of the hillsides, and the geological structure of the entrance area consists of the units mixed with sand, clay, and silt. In addition, the boreholes and the surface monitoring results show that the groundwater is at a high level.

\section{Slope STABILITy ANALYSIS}

To perform the slope stability analysis of Sabzkuh tunnel entrance, a limit equilibrium method was employed using Slide 5.0 Software (2010) 4 and the numerical analysis using FLAC/Slope [5] and the safety factor of the slope stability was measured in both static and pseudo-static conditions. The input parameters of the soil for these applications are shown in Table 1. The slope was designed with berms of 4 meter in width and 8 meters in height each. The slope for the two lower steps was set as 1:1 and for the two higher steps was set as $1: 2$ (horizontal).

\subsection{LIMIT EQUILIBRIUM ANALYSIS}

Given the geological conditions of the region under study, which was made of heterogeneous soils, Morgenestern-Price Method (Half-sine function) was used to perform the stability analysis of the Sabzkuh tunnel entrance.

\section{Stability analysis (Slide 5.0 Software)}

The tunnel entrance cross-section was estimated using Slide 5.0 [4] by including the effects of groundwater and the pseudo-static seismic analysis. Given the high seismicity potential of the studied region, the horizontal seismic coefficient was set as 0.5 and the minimum safety factor was set as 1 . The critical circular cutting surface was automatically created and the safety factor was calculated under different conditions. As it can be seen, the quasi-static slope safety is generally smaller than that of the static condition. Also, the presence of the underground water in the slope can reduce the safety factor by almost $30 \%$.

\subsection{NumERICAL ANALYSIS}

\section{Stability ANALYSis (Flac/SlOPE)}

Due to the advantages of the slope analysis using numerical analysis compared to the limit equilibrium analysis, the slope stability analysis was performed using Flac/Slope Software [5, which is a numerical software that works based on finite difference method. This software is capable of calculating the safety factor of slopes by reducing soil shear strength at different stages to the slope failure. The stability analysis for the cross-section in question was performed for static and pseudo-static conditions and in the presence of water. Table 1 shows the calculated safety factor.

\subsection{Slope StABILITy ANALYSIS RESUlts}

A comparison of the slope stability safety factors in the limit equilibrium analysis and the numerical analysis shows that the safety factor obtained in the numerical analysis is lower than that obtained through the limit equilibrium analysis. In addition, the complex geometry slope, the presence of water in the slope and the inclusion of the earthquake effects in both methods can reduce the slope stability safety factor [6]. The safety factor calculated from the limit equilibrium and numerical analysis are shown in Table 2 .

However, both methods are disadvantageous as they do not consider the effects of the tunnel excavation on the slope stability. Therefore, it can be concluded that the slope stability calculations, taking into account the tunnel structure in slope, is a full three-dimensional problem and using two-dimensional analysis methods makes the slope stability calculations unreliable.

\section{Slope instability monitoring}

Safety, reliability, the optimization of the design, and the evaluation of its effectiveness, the calibration of the employed model, the evaluation of the maintenance system, the prediction of failure and displacement are among the main objectives of the monitoring of geotechnical structures. One of the most primitive methods of slope monitoring is a visual inspection 


\begin{tabular}{lccc}
\hline Construction materials & $\gamma\left(\right.$ ton $\left./ \mathrm{m}^{3}\right)$ & $\varnothing($ deg. $)$ & $C(\mathrm{kPa})$ \\
\hline ML & 1.96 & 17 & 28 \\
SC-SM & 1.99 & 29 & 5 \\
CH-CL & 1.80 & 17 & 0.00 \\
\hline
\end{tabular}

TABLE 1. Physical and mechanical features of the slope soil.

\begin{tabular}{llc}
\hline & analysis & safety factor \\
\hline \multirow{4}{*}{ limit equilibrium analysis } & static without groundwater & 1.68 \\
& static with groundwater & 1.39 \\
& pseudo-static without groundwater & 1.22 \\
& pseudo-static with groundwater & 1.03 \\
\hline \multirow{2}{*}{ numerical analysis } & static without groundwater & 1.64 \\
& static with groundwater & 1.22 \\
& pseudo-static without groundwater & 1.13 \\
\hline
\end{tabular}

TABLE 2. The safety factor calculated from the limit equilibrium and numerical analysis.

by geotechnical engineers and geologists. The implementation of reinforced concrete slabs covering the surfaces of the slopes and berms led to the inaccuracy of visual inspections and observations. Upon the completion of the excavation and concrete slope cover and before starting the tunnel excavation, some cracks were observed on the surface of concrete slab covers and in the slope surface water sewage channel, which indicated the displacement in the slopes.

This caused the alarm for geotechnical engineers to design a monitoring system using mapping points for monitoring slopes. For this purpose, nine settlement markers were installed on the surface along the tunnel and the berms and the monitoring of them was carried out by surveying (Figure 3). Readings of those markers were taken at regular intervals to check for any signs of settlement or heave. The results of the monitoring showed some displacements in both $\mathrm{Z}$ and $\mathrm{Y}$ directions.

\section{TUNNEL COLLAPSE AND SLOPE FAILURE}

The excavation operation of the T1 part of Sabzkuh tunnel was generally performed below the groundwater levels. Because of the excavation operation in the saturated ground, the pore water seeped into the created cavity. On the one hand, the flow of the groundwater reduced the quality of geotechnical parameters of the soil mass around the tunnel, but, on the other hand, reduced the effective stress around the tunnel. This problem along with facing the old landslide surface with complex geological stratification, and inappropriate excavation pace, led to the instability on the tunnel crown. Encountering these areas at a distance of $35 \mathrm{~m}$ along the tunnel simultaneously led to local collapses in the forefront of the excavation operation and the rapid development of collapses in less than 8 hours towards the tunnel crown, creating a chimney-like cavity at the top of the tunnel and eventually leading to the slope failure. In addition, the activation of the old landslide surface caused the mass smoothening of about 1000 cubic meters of soil from the collapsing area into the tunnel exterior and the development of the cavity into the entrance slope (Figure 4).

\section{THE SURVEY PHASE}

After the tunnel collapse, given the size and complexities of continuing the excavation process, a working group of experts consisting of geological, geotechnical, and structural engineers was formed to investigate the possible causes of the collapse and how to pass through the collapsing zone. They also analysed factors affecting the slope stability and the tunnel collapse by conducting surface and subsurface studies and back analysis. The following sections addressed the reasons for the tunnel collapse.

\subsection{Slope TOPOGRAPHY AND GEOMETRY}

Since the gravity component in steep slopes increases the shear stress, the slope topography and angle is the main feature of slopes in terms of sensitivity to landslide and risk assessment. Therefore, slopes with lower angles are less likely to undergo failure [7]. Changes in the slope geometry reduce the shear stress in the soil yielding and intensify the slope instability. The problem of land acquisition by the employer affected slope geometry, so that the tunnel portal was designed with steep slopes and high altitude. This reduced the safety factor of the slope stability.

\subsection{Geology}

Placing geological units with different permeability and strength together and providing a poor surface with steep slope and improper orientation of the soil layers are among factors affecting the slope instability and the collapse in the tunnel. Stratified steep soils are prone to landslides and displacement along the 


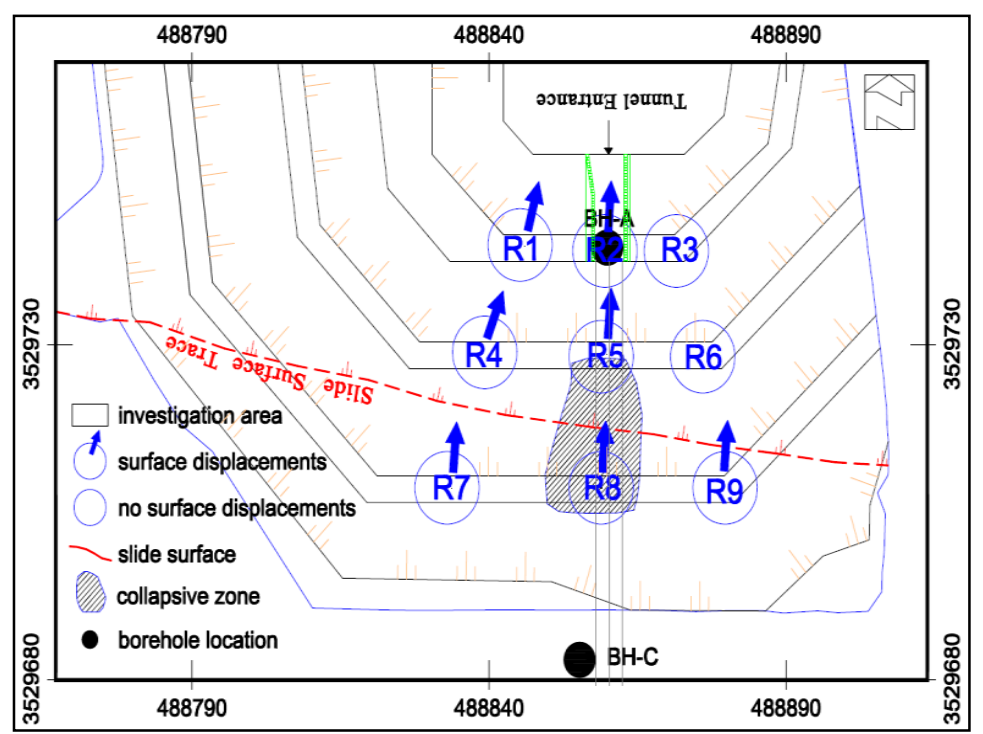

FIGURE 3. The location of monitoring points in the tunnel portal.
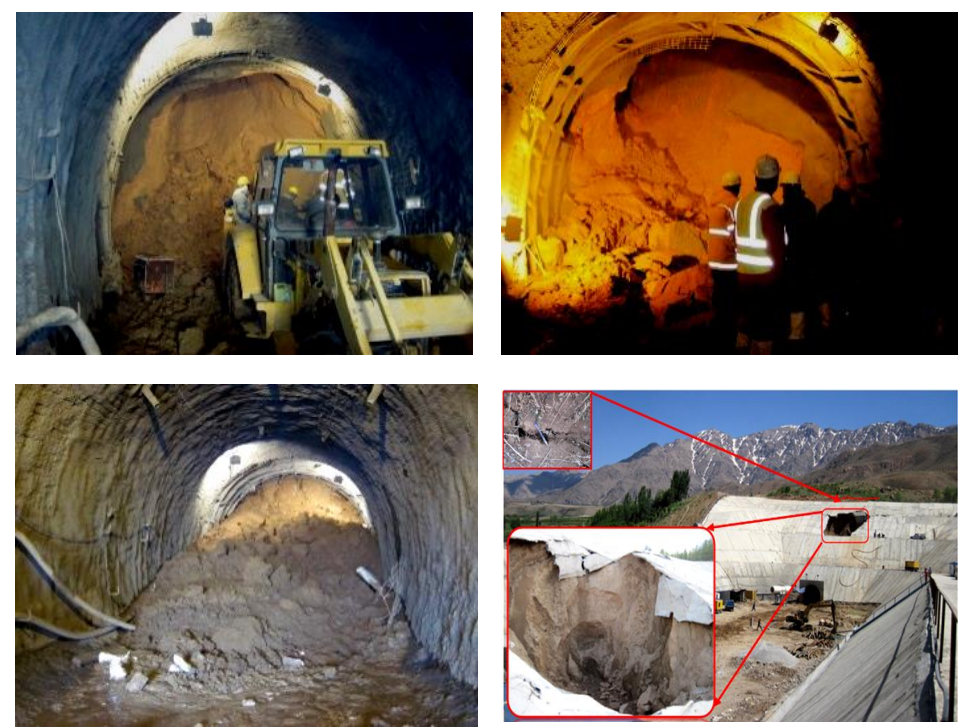

Figure 4. The development of the collapse and slope failur.

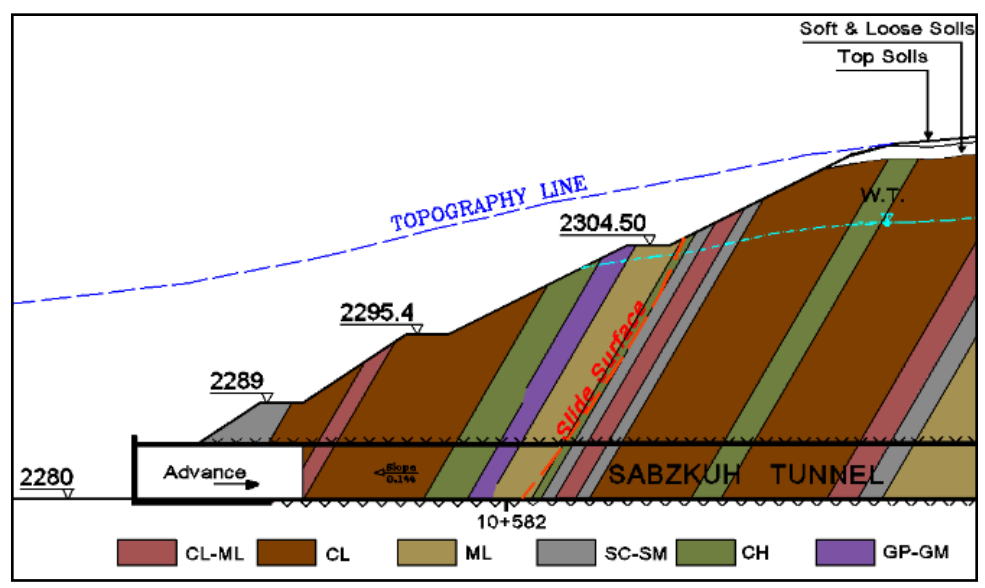

FiguRE 5. The geological characteristics of the soil layers of tunnel portal. 
weak layers. Thus, special attention must be paid to the geological aspects when performing the slope stability assessment. In Figure 5 the geological characteristics of the soil layers, the slope of the layers, the groundwater level, and the different levels of overburden of the tunnel are displayed at a distance of 350 meters from the tunnel entrance (Figure 5 .

\subsection{HYDROLOGY}

Water is always considered as an important factor in the slope instability. Climatological studies, periodic explorations of boreholes and springs in the studied region and the observation of aquifers when excavating the tunnel entrance, all of them showed the high groundwater levels in the region. A nonstop rainfall just one week before the collapse resulted in the water infiltration into the pores of the soil masses. On the one hand, this increased the pore water pressure and reduced the effective tension among the soil grains and, on the other hand, the additional weight of the slope ingredients, due to the saturation, increased the shear stress between the slope layers. Ultimately, the water infiltration into the faults increased the hydrostatic pressure so that the gravity drainage system alone could not meet the water discharge requirements inside the slope.

\subsection{HISTORY OF LANDSLIDES AND TUNNEL EXCAVATION}

To avoid the adverse effects of landslides during the tunnel excavation, a distance between the tunnel axis and the sliding area was studied. This requires a good understanding of the interaction between the landslide and tunnel excavation, which must be investigated in terms of controlling displacements and the effects of stress through long-term monitoring and numerical analyses.

The results of ground surface and subsurface studies show that the axis of Sabzkuh tunnel has an angle of about 30 degrees with the old sliding surface. Given that the tunnel axis is parallel to the slope direction, the shear deformation occurs along the linear profile. In addition, the angle between the sliding surface and the tunnel axis resulted in the development of the shear zone. However, the effects of the tunnel excavation were not considered in the slope stability analysis. The results of numerical analyses and limit equilibrium show that the sliding wedge is located across the tunnel route and there is a possibility of the slope instability as a result of the tunnel excavation.

After summarizing the data from identification and survey stages, the three-dimensional slope stability analysis was performed by considering the sliding surface, the new geological model, and the effects of the tunnel excavation on the slope stability. The results of this analysis predicted the tunnel collapse [2]. Therefore, as indicated by the complex geological model, conducting complementary studies and revising the excavation method was deemed necessary.

\subsection{GEOPHYSICAL STUDIES}

The present study used geoelectrical techniques in conjunction with seismography to analyse the slope instability and identify sites with landslide and fault potentials.

\section{Geoelectrics}

Electrical resistivity methods are among the most widely used conventional methods of geophysical explorations that are highly effective in both engineering studies and exploring various geological features. Electrical resistivity methods are also frequently used to explore landslides due to their accuracy and speed. The main rationale behind the use of geoelectircal techniques is their high resolution power to identify aquifers across the collapse areas as these aquifers accelerate the slide of instable masses.

Geoelectrical explorations that were performed in this study used combined resistivity profiling (CRP). This technique is able to detect heterogeneities and discontinuities, such as fault zones and intersections, in the studied area. In order to evaluate the variation in the resistance of alluvial layers and detecting them based on their resistivity and their possible rupture to a distance of 350 meters from the entrance of the tunnel, a total number of $82 \mathrm{CRP}$ stations were used on four main exploration lines called lines 1 to 4 with a north-south orientation. In addition, a total of 12 offset lines, termed as X1 to X12, were marked on the location map (Figure 6).

\section{SEISMOGRAPHY}

In order to perform a low-depth reflective survey across the survey lines in the site of Sabzkuh water tunnel, the following operating parameters were defined as shown in figure 9

\section{REMEDIAL SOLUTION}

In landslides, in which the used materials are mainly debris and hillside alluvia, the collapsing area is not generally reinforced under the alluvial deposits and a shell is located in substances, such as silt and materials with low adhesion to rock fragments in different sizes. Given the negative effects of the slope materials and sliding areas in the alluvial slopes and hillside debris, the slope stability is vulnerable to many different factors. Therefore, the procedure taken to stabilize the landslide is of a high importance [8].

\subsection{PAssing through the COLlapsing AREA OF THE TUNNEL}

In order to pass the collapsing area, the causes and mechanism of similar collapses were studied by taking into account technical and economic considerations. For this purpose, the results of second stage excavation of Istanbul Metro between Unkapani and Yenikapi were studied. Given the almost similar excavation method and geological conditions in both projects, and also the efficiency of umbrella arch method (UAM) 

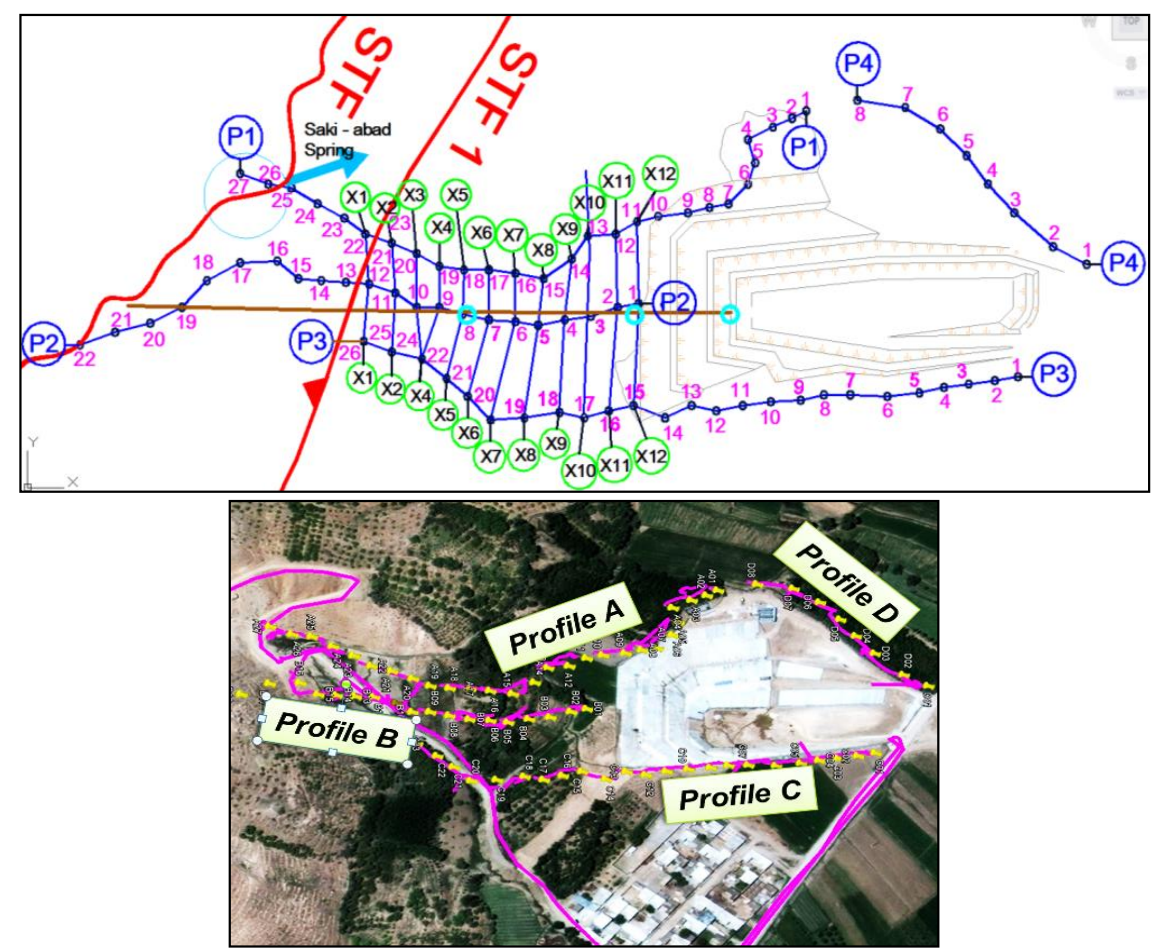

Figure 6. Profile plan of geoelectrical explorations.
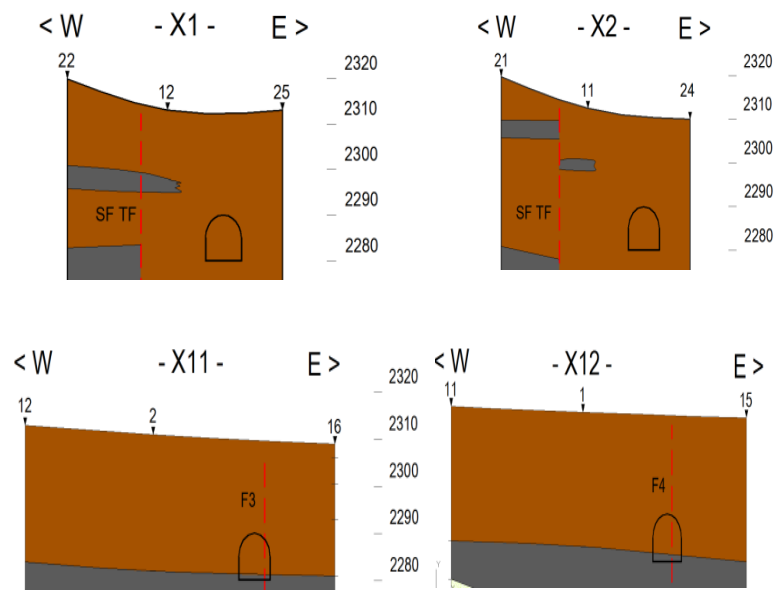

\begin{tabular}{|l|c|}
\hline \multicolumn{2}{|c|}{ Geoelectric Section CRP } \\
\hline Section Name & -1 - \\
\hline Sounding Number & 22 \\
\hline Section Direction & $<\mathrm{W}$ \\
\hline Layer Boundary & \\
\hline Fault & \\
\hline Collapsed Soll & \\
\hline Borenole & \\
\hline Alluvial Terrace & \\
\hline Sandy Clay & \\
\hline $\begin{array}{l}\text { Limestone with } \\
\text { Shale Interlayer }\end{array}$ & \\
\hline Shale with limestone & \\
\hline $\begin{array}{l}\text { Breccated Dolomite } \\
\text { with gypsum }\end{array}$ & \\
\hline Breccated Dolomite & \\
\hline
\end{tabular}

Figure 7. The cross-section of geoelectrical explorations. 

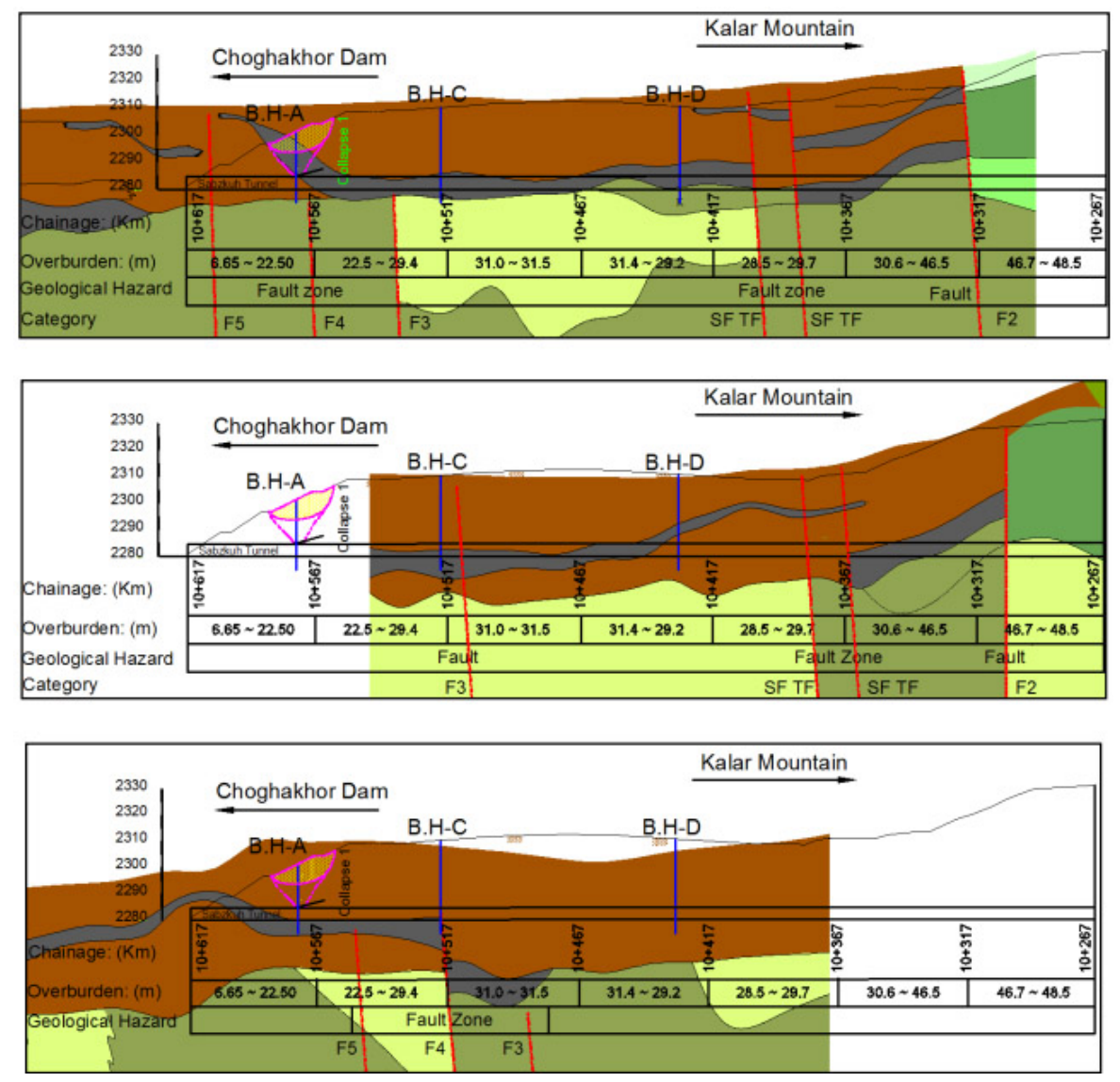

FiguRE 8. Profile plan of geoelectrical cross-sections.

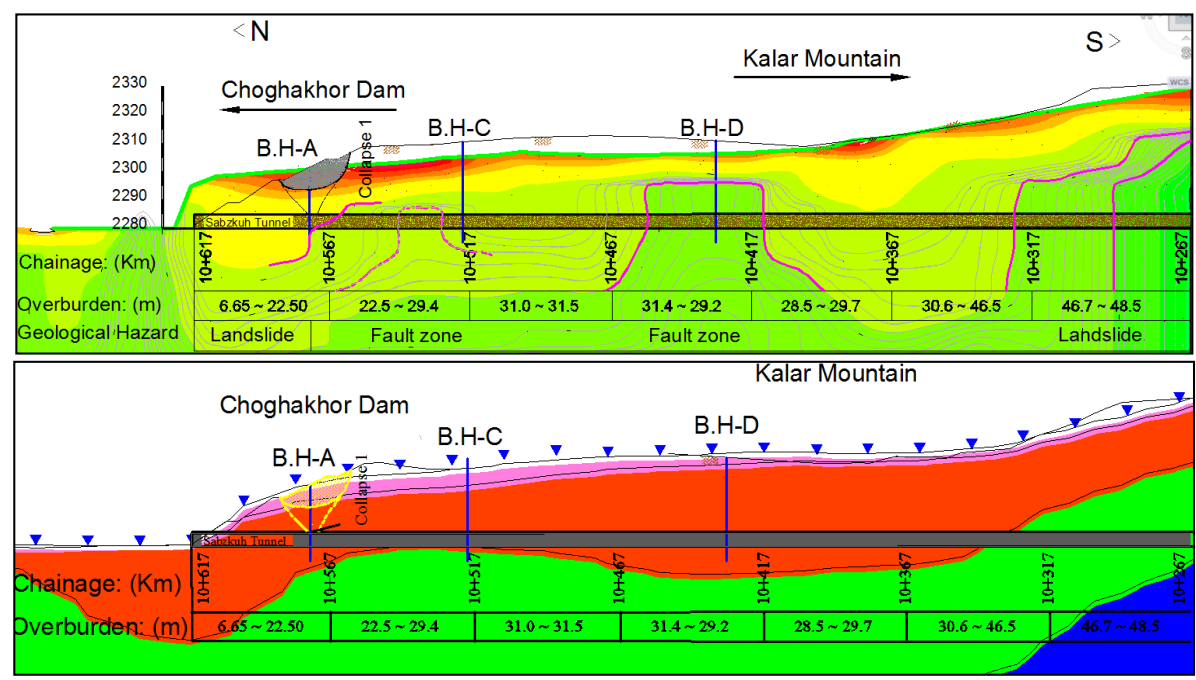

\begin{tabular}{|l|c|}
\hline Section Name & -Refraction Seismic - \\
\hline Sounding number & $\mathbf{V}$ \\
\hline Section Direction & $\mathrm{N}$ \\
\hline Layer boundry & \\
\hline Velocity Layer 1 & $500 \sim 800$ \\
\hline Velocity Layer 2 & $800 \sim 1600$ \\
\hline Velocity Layer 3 & $1600 \sim 3200$ \\
\hline Velocity Layer 4 & $3200 \sim 3500$ \\
\hline
\end{tabular}

\begin{tabular}{|l|l|}
\hline \multicolumn{2}{|c|}{ Refraction Seismic P1\&P2 } \\
\hline Borehole & B.H. \\
\hline Section Direction & $<\mathrm{N}$ \\
\hline Topography Line & \\
\hline Tunnel's level surface & \\
\hline Layer Boundary & \\
\hline Collapsed Soil & \\
\hline
\end{tabular}

Figure 9. Seismic reflection survey profile. 
in sensitive regions, this method was proposed by the designers 9 . Then, in the implementation phase of this method in the collapsing area in Section T1 of Sabzkuh tunnel, IPE180 with $15 \mathrm{~cm}$ spacing and a length of 9 meter was used based on the design requirements, implementing the arch support technique and results of the finite element analysis [2].

\subsection{Slope improvement}

Given the high groundwater levels and annual rainfalls in the region as well as the water seepage through the irrigation of farming lands, two types of drainage systems were proposed: (1) installing drainage systems with a long length in the entrance (2) installing drainage systems inside the tunnel to lower groundwater levels. A pumping system was used in the route of Section T1 to lower groundwater levels and to reduce risks during the tunnel excavation. The surface water collection system in the tunnel entrance was also repaired and improved. Besides, the irrigation of gardens around the tunnel entrance came to a halt to reduce the effects of water leakage in this area. Finally, micro-piles and nailing were also employed to stabilize the slope.

\subsection{DEBRIS FLOWS}

In April 2013, coinciding with the implementation of the drainage system in the slopes and before the start of the tunnel excavation, after heavy rainfall and rapid melting of snow because of a spike in temperature in the surrounding mountains, signs of the increased stress imposed on the pre-support systems and the arch support technique were observed (Figure 10).

Following this, just one day after the heavy rainfall, the second event occurred. Within 35 meters of the tunnel entrance, about 500 cubic meters of soil in the form of debris flows started to move from the tunnel crown toward the entrance of the tunnel in 8 hours (Figure 11). The samples taken for the materials showed that more than 50 percent of the materials included gravels, sand, and silt and only a small percentage of clay. These materials started to flow down under the influence of the steep slope of layers, the gravity, and gravitational forces accompanied by the increased leakage force. In addition, another reason for the occurrence of debris flow was the presence of an old landslide in this area, which placed unstable soil masses on steep slopes. The infiltration of water flow over the old landslide lubricated and smoothed the sliding materials. Besides, the impacts and shocks from the arch support system stimulated sliding masses in the slope followed by decreased resistance forces, which resulted in debris flows inside the tunnel.

This resulted in the expansion of the cavity developed in the entrance and intensified the slope instability. Besides, the implemented pre-support system moved down about $60 \mathrm{~cm}$, but it was not broken due to its high rigidity. After the discharge of sliding materials inside the tunnel, so as to prevent re-occurrence of the problem and reduce the pressure from the excavation, the forefront was plugged with plastic concrete with a thickness of $10 \mathrm{~m}$ before resuming the excavation.

\subsection{Filling the COLlapsing CAVity}

To fill the cavity developed in the slope by meeting the slope stability requirements and minimizing stresses applied to the pre-support system, three options were proposed, (Table 3 ) and the three-dimensional modelling was performed using FLAC-3D Software [10]. The input parameters of the soil for the modelling are shown in Table 1

In order to model the filling conditions of the collapsing cavity, it was divided into two parts: The first part started from the tunnel crown to a height of 5 meters and the second parts included areas from a height of 5 meters to a height of 11.8 meters (Figure 12 ).

In the next stage, the properties of filling materials were studied and the displacement and maximum stress on the crown were calculated. The technical and economic results indicated that the first option is not favourable because of the displacement and high stress imposed on the support system. From the second and third options, the second option was selected due to lower displacement and stresses applied to the tunnel crown and its economic advantages. As shown in Fig. 13 the maximum calculated displacement in the tunnel crown after filling the collapsing cavity with soil and lightweight aggregate concrete (LWAC) is about $20 \mathrm{~mm}$.

In order to validate and verify the results of the numerical analysis, a convergence station was installed in the centre of the tunnel crown in the collapsing area and the displacement of the support system during the filling process was monitored and recorded. The maximum displacement recorded in the tunnel crown was $8 \mathrm{~mm}$. The results of the monitoring are shown in Figure 14

\subsection{The tunnel excavation Method}

The cross-excavation method resulted in the development of the plastic zone around the tunnel and the tunnel stability was deteriorated after confronting the old sliding surface, leading to the slope failure. The forefront displacement was controlled by changing the cross-excavation method into Sequential Excavation Method (SEM) and performing the reinforcement measures in the forefront including the use of fiberglass nails, traditional cement injection around the tunnel, an early installation of the apron wall, the improvement of the drainage system, and regular monitoring inside the tunnel.

\subsection{Monitoring STAGes}

In order to evaluate the performance and control the optimal progress of the project based on the rein- 


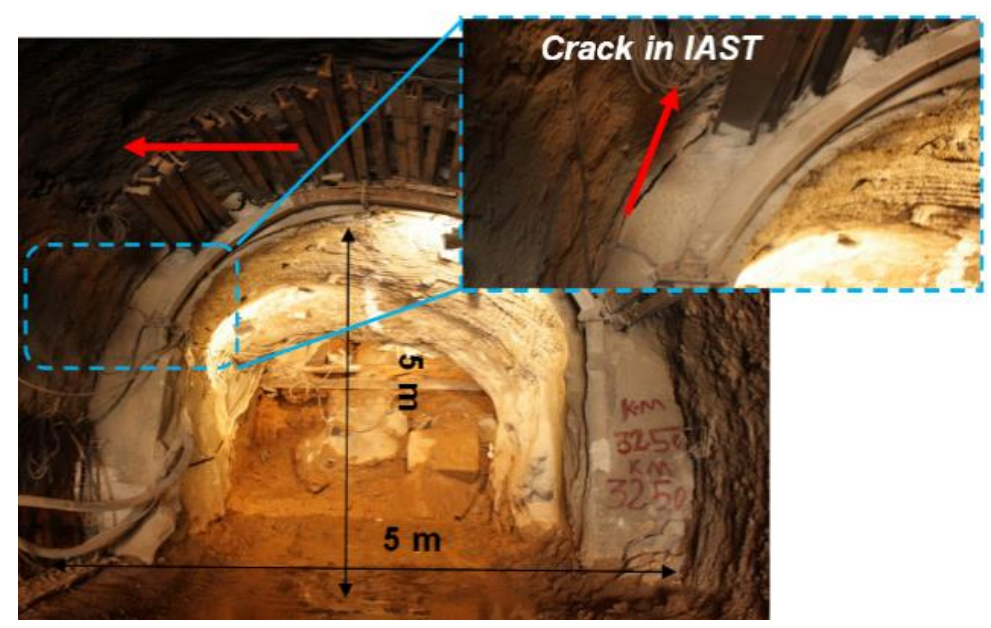

FiguRE 10. Cracking in the pre-support system.

\begin{tabular}{clcc}
\hline \multirow{2}{*}{ Options } & Materials & \multicolumn{2}{c}{ Special weight $\left(\mathrm{KN} / \mathrm{m}^{3}\right)$} \\
\cline { 3 - 4 } & & First phase materials & Second phase materials \\
\hline 1 & Soil & 13 & 18 \\
\hline 2 & $\begin{array}{l}\text { Soil and lightweight } \\
\text { aggregate concrete (LWAC) }\end{array}$ & \multirow{2}{*}{18} \\
\hline 3 & $\begin{array}{l}\text { Controlled low-strength concrete } \\
\text { materials (CLSM) and soil }\end{array}$ & 10 & 18 \\
\hline
\end{tabular}

TABLE 3. Properties of the proposed options.

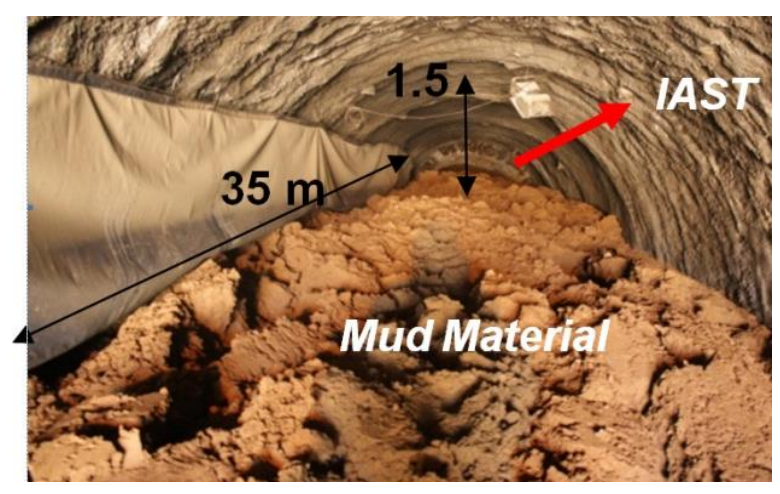

FiguRE 11. The mud flow running into the tunnel.

forcement procedure, the slope monitoring continued through visual visits and geodetic surveying to make sure that the instability would not be further developed in the long run. As it is shown in figure 14 before the start of the reinforcement operations, the displacement rate was on the rise. The displacement along the $\mathrm{Y}$ axis was greater than along other axes due to a higher sliding potential. The maximum displacement was observed in Pin No.1, which was caused by a high pore-water pressure in this area of aquifers that were observed during the slope excavation. After performing each step of the improvement in the tunnels and the slope, displacements slowed down. After the completion of the improvements and with the start

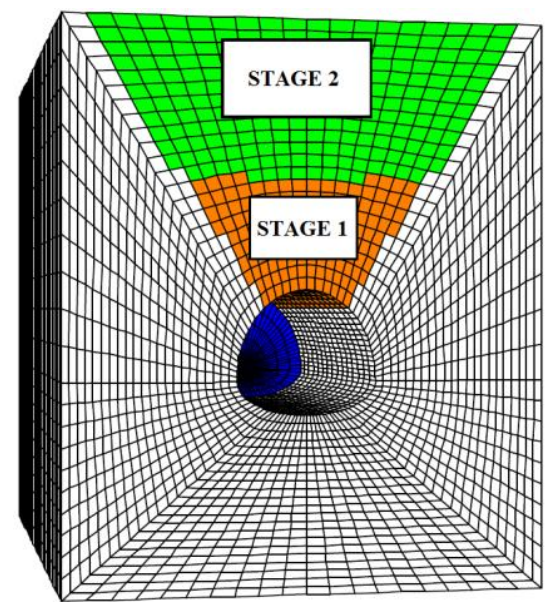

Figure 12. Two stages of filling the collapsing cavity above the tunnel crown.

of the stage excavation, displacement rates became almost stagnant (Figure 15).

\section{Discussion AND CONCLUSION}

This article presents a case study of the activation of a landslide resulting from the tunnel excavation in an area with complex geological conditions and active tectonics that were not identified before starting the tunnelling operation. The excavation of the tunnel portal in problematic areas has always been associated 

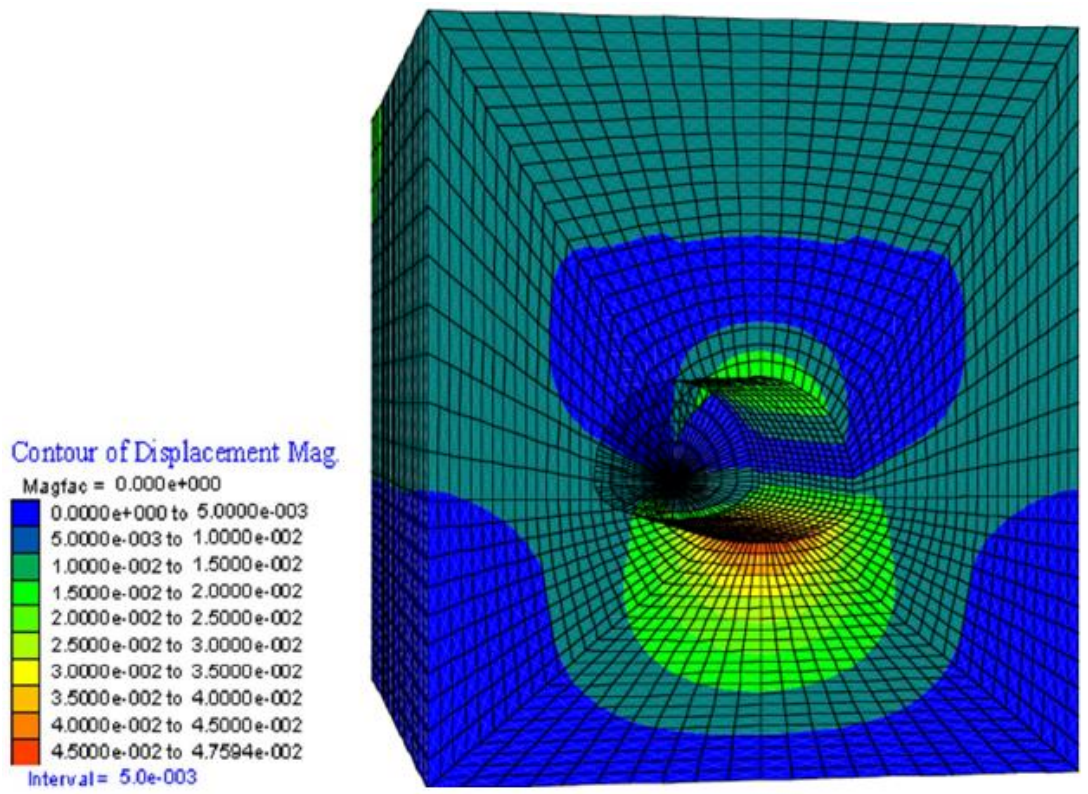

FIGURE 13. The displacement changes around the tunnel after filling the collapsing cavity with the second option.

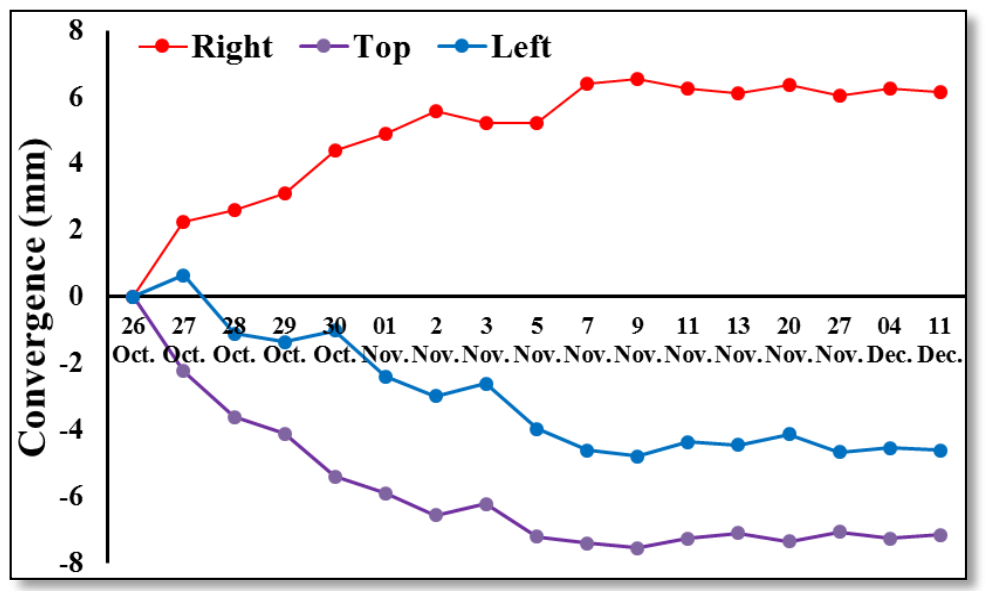

FiguRE 14. The displacement curve of the convergence station in the centre of the tunnel crown in collapsing area.

with some challenges, which implies the necessity of the slope management and planning. Accordingly, the following points must be taken into account for the tunnel excavation:

- Two boreholes A and B had been drilled for the design of the Sabzkuh tunnel portal to identify underground excavation layers. Given that the excavation data were collected from sporadic points, they were not helpful in estimating the changes in the underground layers between these two borehole points. Therefore, integrating the results of ground and underground studies is necessary in regions with complex geological conditions in order to pan an appropriate geological model.

- The tunnel excavation resulted in the redistribution of stress in the earth surrounding the tunnel excavation and the activation of an old landslide. Therefore, the effects of the tunnel excavation should be considered in the slope stability analysis.
- Monitoring and controlling displacement in complex and problematic areas are of high significance for exploring and predicting necessary actions and detecting the causes of abnormalities in the slope and the tunnel support system through measuring surface topography, visual and inspections, piezometer, convergence-meter inside the tunnel, geotechnical laboratory studies, and geological mapping.

- The excavation and maintenance techniques can affect the stability of the slope. As such, the interaction between the excavation method and the slope stability should be considered in the modelling.

- In mountainous areas, detailed studies need to be conducted in order to identify old landslides, find the optimal route for the tunnel axis, and observe the needed distance from these areas. 

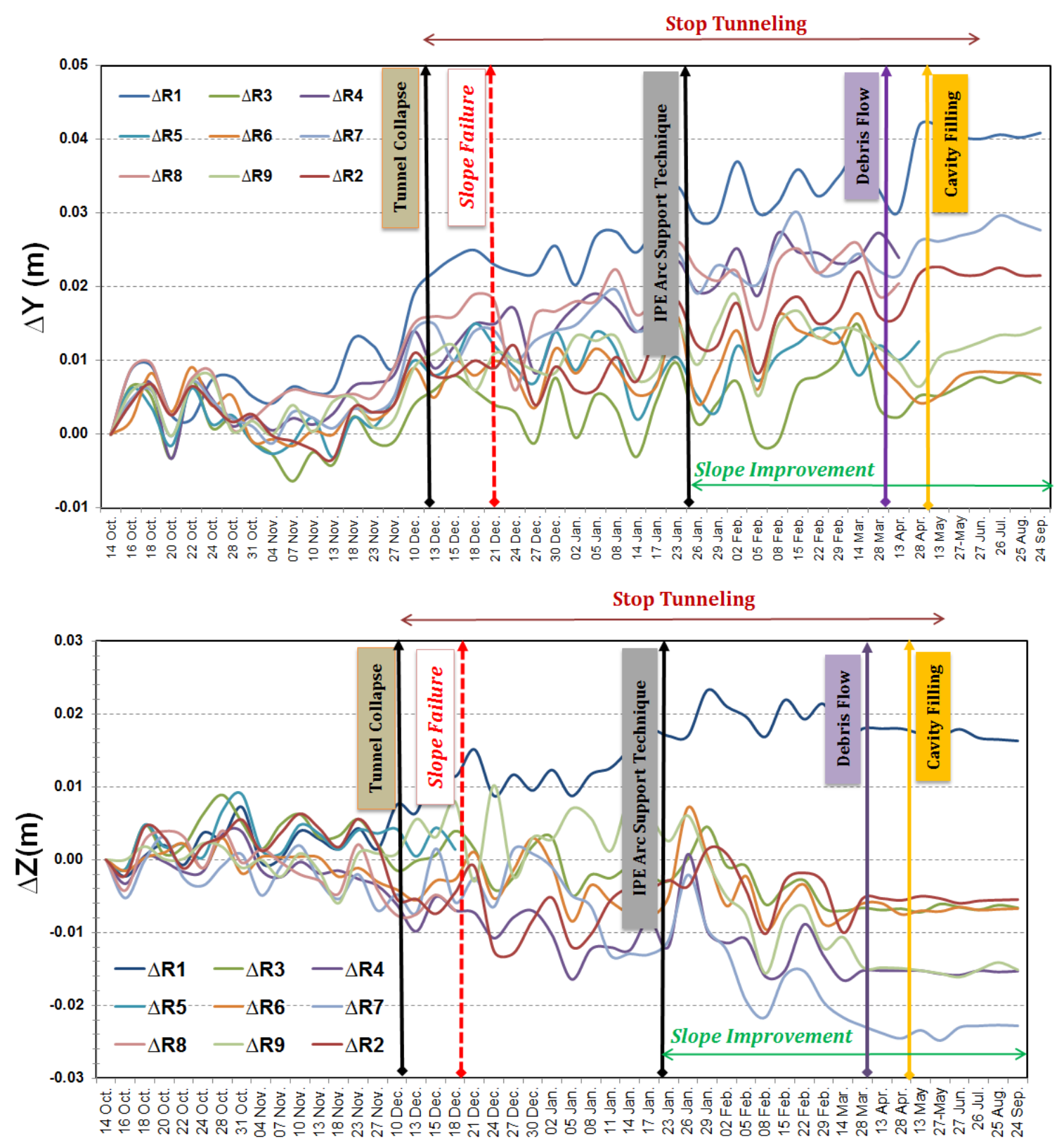

FIGURE 15. The slope monitoring stages.

\section{ACKNOWLEDGEMENTS}

The authors are thankful to the Project Manager of Sabzkuh water supply system, Mr. A. Izadi of F.T.R Engineering Ins. for sharing his vast experience and his guidance.

\section{REFERENCES}

[1] A. Eftekhari, M. Taromi, M. Saeidi. Uncertainties and complexities of the geological model in slope stability: A case study of Sabzkuh tunnel. International Journal of Mining and Geo-Engineering 48(1):69-79, 2014. DOI:10.22059/IJMGE.2014.51807

[2] M. Taremi, A. Eftekhari, M. Saeedi. A study of the reinforcement effect of IPE arc support technique (IAST): A case study of Sabzkuh tunnel. Journal of Engineering Geology 9:2559-2574, 2015. DOI:10.18869/acadpub.jeg.9.1.2559
[3] M. Mannani, M. Yazdi. Late triassic and early cretaceous sedimentary sequences of the northern Isfahan province Central Iran): Stratigraphy and paleoenvironments. Boletín de la Sociedad Geológica Mexicana 61:367-374, 2009. DOI:10.18268/BSGM2009v61n3a6.

[4] R. Geomechanics Software Solutions. Slide software Stability analysis for soil and rock slopes, 2010.

[5] Itasca Consulting Group. Flac Slope Manual, 2002.

[6] M. Cała, J. Flisiak. Slope stability analysis with numerical and limit equilibrium methods. In Conference of Computer Methods in Mechanics (CMM 2003). Gliwice, Poland, 2003.

[7] T. Kritikos, T. Davies. Assessment of rainfallgenerated shallow landslide/debris-flow susceptibility and runout using a GIS-based approach: Application to western Southern Alps of New Zealand. Landslides 12:1051-1075, 2015. DOI:10.1007/s10346-014-0533-6. 
[8] J. Du, K. Yin, S. Lacasse. Displacement prediction in colluvial landslides, three Gorges reservoir, China.

Landslides 10:203-218, 2013.

DOI:10.1007/s10346-012-0326-8

[9] I. Ocak. Control of surface settlements with umbrella arch method in second stage excavations of Istanbul metro. Tunnelling and Underground Space Technology 23:674-681, 2008. DOI:10.1016/j.tust.2007.12.005
[10] M. Itasca Consulting Group. FLAC3D - Fast

Lagrangian Analysis of Continua in 3 Dimensions, 2005. 